How to cite this article:

Hasmin, N. A., Zainol, Z. A., Azizun, N., \& Abd Kadir, N. H. (2020). Mandatory labelling of nanofood and the WTO agreements. Jounral of International Studies, 16, 59-72. https:// doi.org/10.32890/jis2020.16.4

\title{
Mandatory Labelling of Nanofood and the WTO Agreements
}

\author{
${ }^{1}$ Nor Akhmal Hasmin, ${ }^{2}$ Zinatul Ashiqin Zainol, ${ }^{3}$ Najwa Azizun, \& \\ ${ }^{4}$ Nur Hafidah Abd Kadir \\ ${ }^{1,3 \& 4}$ Centre of Foundation Studies, \\ Universiti Teknologi MARA, Kampus Dengkil, Malaysia \\ ${ }^{2}$ Faculty of Law, Universiti Kebangsaan Malaysia, Bangi, Malaysia \\ ${ }^{1}$ Corresponding author: norakhmal5559@uitm.edu.my
}

\begin{abstract}
The labelling of food products that contain new technologies have been carried out to ensure that consumers are well informed on the hazards and uncertainty of the technologies incorporated for food production. Although food labelling is important, the implementation of mandatory labelling measures for nanofood within the domestic legislation is only possible if it is aligned with the regulations of the World Trade Organisation (WTO). This study examines the mandatory labelling measure for nanofood that would be permissible under the WTO agreements, i.e. under the Technical Barriers to Trade Agreement and the Sanitary and Phytosanitary Agreement. This study adopted a doctrinal approach and content analysis that examine the relevant legal provisions in the WTO agreements, proceedings conducted by the WTO, and other documents on nanofood labelling. The findings suggest that the labelling measure amounts to unnecessary barriers to international trade. Moreover, mandatory labelling is not an international labelling standard, while the practice of mandatory labelling was found to be trade restrictive. Some recommendations were presented in this study that provide valuable insights on the implementation of mandatory labelling for nanofood if countries decide to introduce this measures into their food information system.
\end{abstract}

Keywords: Mandatory labelling, nanofood, TBT Agreement, SPS Agreement, barrier to trade.

\section{Introduction}

A sovereign state has principal authority towards its food regulations. A state can adopt and introduce food standards to enhance food safety and protect its citizens from any risks 
associated with food production (Orden \& Robert, 2007; Rahmah Ismail, 2011). Such protection can be provided by improving the provisions of food information, either through mandatory or voluntary labelling measures (World Health Organisation, 2015). Nanofood labelling continues to be a controversial labelling issue. The term nanofood is defined as food that has been cultivated, produced, processed, or packaged using nanotechnology, or with added nanomaterials (Joseph \& Morrison, 2006). However, controversy arises due to the conflicting opinions between nations, particularly between the European Union (EU) and the United States (US).

The EU has subsequently imposed mandatory labelling measure to its member states (D'Silva \& Bowman, 2010). Article 18 (3) of the Regulation (EC) 1169/2011 of the food consumer information (FIC) requires the word 'nano' to be placed next to the name of food ingredients that contain any forms of engineered nanomaterials (ENMs). The objectives of mandatory labelling are twofold; 1) to protect consumers' rights to make informed decisions (European Parliament, 2014), and 2) to protect consumers from potential health and safety risks associated with engineered nanomaterials (ENMs) (Amenta et al., 2015). On the contrary, the US Food and Drugs Administration (FDA) implements a voluntary labelling measure (Snir, 2013). Manufacturers are not obliged to disclose the presence of nanomaterials as the extent of risks associated with nanomaterials have not been scientifically proven (Food and Drug Administration, 2007; Chuah, Leong, Cummings \& Ho, 2018).

Mandatory labelling for nanofood has not been adopted as an international food labelling standard by the Codex Alimentarius Commission (CAC) and Codex Committee on Food Labelling (CCFL) (Codex Alimentarius, n.d.). There have been attempts to standardise food labelling by the International Standard Organisation (ISO) through a standard issued on Guidance for Labelling for Consumer Products Containing Manufactured Nano-Objects (ISO/TS 13830:2013). However, the ISO guidance is a voluntary labelling standard (International Standard Organisation, 2013) and hence, its implementation is dependent on the manufacturers' discretion. Although labelling has not been recognised as the international labelling standard, the implementation of such measure within the domestic regulatory framework will directly affect international trade (Gruère, 2011; Capon, Gillespie, Rolfe, \& Smith, 2015). Product labelling is a standard that may trigger trade restrictions, i.e. nontariff measure (Ahmad Shafiee \& Yeon, 2016). This standard may restrict international trade with countries that implement different labelling measures (Keane, 2006; Thow, Jones, Hawkes, Ali \& Labonté, 2017).

Non-tariff measures that are imposed between members of the WTO are subjected to further review by the WTO committee. The review aims to protect other WTO members from any unnecessary barriers to international trade and for the resolution of trade dispute (Keane, 2006). This study examines the mandatory labelling of nanofood that is permissible under the WTO agreements. The discussion in this study provides valuable insights on the status of mandatory labelling measure for nanofood from the perspective of the WTO for countries that wishes to introduce similar labelling measure. This study adopted the qualitative 
research method, whereby doctrinal analysis was employed to examine the relevant laws on nanofood labelling, provisions of the WTO agreements, and proceedings conducted by the WTO on international trade disputes. This study consists of four parts. Following the introduction, the first part is the literature review. The second parts presents the analysis of the WTO agreements that are relevant to nanofood labelling. The third part examines the consistency of two WTO agreements with mandatory labelling of nanofood, namely the Technical Barrier to Trade (TBT Agreement) and the Sanitary and Phytosanitary Agreement (SPS Agreement). The last part discusses the findings and suggest recommendations for future works. This study concludes that mandatory labelling of nanofood is trade-restrictive and creates an unnecessary barrier to trade under the WTO agreements.

\section{Literature Review}

There is a lack of literature that discusses nanotechnology under the WTO agreement. The systematic search using the search strings 'nanotechnology', 'WTO', and 'agreement' on Scopus and Web of Science databases had only yielded two articles. The study conducted by Abdollahi and Azar (2019) highlighted that nanotechnology products that are traded daily were subjected to the WTO agreements, and further concluded that the agreements had established a fair balance between the risks and benefits of nanotechnology. Moreover, Karlaganis and Liechti (2013) asserted that the governance of products that contain nanochemical were regulated under the UN Strategic Approach to International Chemicals Management (SAICM), and further examined the relationship between SAICM and WTO agreements. Although these studies emphasized nanotechnology labelling, the main focus was on nano-chemical labelling.

Searches on another database found several articles on the trade of nanotechnology products under the WTO agreements. Thayer (2005) analysed the applicability of the SPS Agreement, and found that the SPS Agreement is relevant if the measure imposed on nanotechnology products was to protect humans or animals from the toxicity of nanomaterials. The provisions in the SPS agreement balances the risks and benefits of nanotechnology as the agreement is reliant on scientific evidence. However, the provision that relates to labelling was not discussed. D'Silva and Bowman (2010) highlighted the trade implications of nanotechnology consumer products labelling from the perspective of WTO without analysing the provisions in the WTO agreements. Similarly, Grieger (2016) discussed the international implications of labelling as a barrier to trade without including the provisions of the WTO agreements. The study conducted by Karlaganis (2019) suggested that Asia and the EU have declared the incompatibility of mandatory labelling with the WTO agreements, and considers mandatory labelling to be a technical barrier for trade. Essentially, this became the main reason that halted efforts to include nano-labelling in products. The discussion on mandatory labelling was in relation to general nanotechnology products, and was not specifically on nanofood. Therefore, it is crucial for this paper to explore the measure of mandatory labelling for nanofood from the perspective of WTO. 


\section{Relevance of WTO Agreements to the Mandatory Labelling Measure for Nanofood}

The WTO was established in 1995 after several negotiations from 1986 to 1994, known as the Uruguay Round. The WTO was the successor of the General Agreement on Tariffs and Trade (GATT) (World Trade Organisation, 2019). As of September 2018, it was comprised of 164 member states that represented 98 percent of international trade activities (World Trade Organisation, 2018). It is the largest and only international organisation that provides a common institutional framework for rules and policies on international trade. The rules and policies are embedded within the WTO agreements and associated legal instruments, and include a total of thirty agreements and separate commitments (World Trade Organisation, 2014). However, none of the thirty WTO agreements deal with food labelling (Keane, 2006). It is suggested that the mandatory labelling measure is a form of regulation that affects free trade of foods between member states. Therefore, to validate the labelling measure adopted into the national legislation, the two requirements of the WTO agreements must be met, i.e. under the provisions of the TBT Agreement and SPS Agreement (Li, 2014).

\section{The TBT Agreement and Mandatory Labelling of Nanofood}

The TBT Agreement came into effect concurrently with the establishment of the WTO in January 1995, under Annex 1A of the Agreement Establishing the World Trade Organisation (World Trade Organisation, 2014). The agreement deals with non-tariff measures. The scope of the agreement is to ensure that technical regulations imposed by member states are not discriminatory. Furthermore, it avoids unnecessary barriers to international trade and allows member states to implement regulatory measures for the best interest of their nation and citizens (UNCTAD, 2003).

The implementation of mandatory labelling measure for nanofood is classified as a form of technical regulation under the TBT Agreement. Annexe 1.1 states that technical regulation to trade occurs when a WTO member requires specific terminology, symbols, packaging, marking, or labelling measures when applying to a product, process or production method. If WTO members insist on the implementation of mandatory labelling measure, the member states must demonstrate that the labelling measure is align with the rules of the TBT Agreement. Article 2 is the most important provision as it presents the conditions that would permit technical regulation. Three sub provisions, namely Article 2.1, Article 2.2 and Article 2.4, are analysed.

Article 2.1 mandates that "members shall ensure that in respect of technical regulations, products imported from the territory of any Member shall be accorded treatment no less favourable than that accorded to like products of national origin and to like products originating in any other country (emphasis added)". The provision allows members to adopt technical regulation, as long as its implementation does not discriminate or lead to less favourable treatment to similar products. Therefore, member states must ensure that: i) nanofood and conventional foods are not similar products, and ii) the mandatory labelling 
measure does not cause less favourable treatment or discrimination on the imported product.

Member states must demonstrate that nanofood is not equivalent to conventional foods. This can be achieved by using the guideline established by the WTO working party, in the case of Border Tax Adjustments (1970) L/3464, to evaluate the 'likeness' between products. Additionally, the working party has outlined four conditions that must be taken into consideration: (i) the physical properties of the products, (ii) the extent to which the products are capable of serving the same or similar end-uses, (iii) consumers' tastes and habits which are comprehensively termed as consumers' perceptions and behaviours, with respect to the products, and (iv) the international classification of the products for tariff purposes.

In general, the physical appearance of nanofood and conventional food are similar. For instance, the appearance of apples coated with nanocoating is identical to the apples without nanocoating, although there is a clear distinction in the physical properties. The apples with nanocoating have a longer shelf life as compared to the conventional apples. Nanocoating with antimicrobial, such as nano zinc oxide, has been proven to extend the shelf life of fruits. This could not be achieved with the use of zinc oxide in bulk size (Lakshmi et al., 2018). Manufacturers prefer to incorporate ENMs in food processing or agricultural industry due to the unique advantages of ENMs that are more resistant to microbial (Hoseinnejad, Jafari, \& Katouzian, 2018). This further improves delivery and absorption system for food supplement (Jampilek, Ko, \& Kralova, 2019) with excellent anti-caking agent (Peters et al., 2016) that enhances the stability of colour, flavour profiles and sweetness during processing (Ramkumar, Vishwanatha, \& Saini, 2019) which could not be achieved by the same materials in its macro size (Ravichandran, 2010). Hence, ENMs and macroscale materials serve different end-uses. Moreover, nanofood is different than conventional food, particularly with respect to safety. There is increased concern over the adverse effects of ENMs in food on the health and safety of humans (Tang et al., 2015; Ranjan, Dasgupta, Singh, \& Gandhi, 2019).

In relation to consumers' taste and habits, this study is unable to ascertain their perception as this can only be identified by conducting a systematic survey on consumer's preference. The international tariff classification, i.e. the Harmonised System Code (HS-Codes) does not provide any distinction between nanofood and conventional food. This is because the classification is based on the types of food, rather than food materials or ingredients (United Nations Trade Statistic, 2017).

However, if the WTO panel asserts that nanofood and conventional food are the same products, mandatory labelling measure remains valid as long as it does not cause less favourable treatment towards similar imported products. In the case of the United States Certain Country of Origin Labelling Measures (2001) WT/DS135/AB/R (US-COOL), the Appellate Board stated that the country of origin labelling (COOL) measures imposed by the US had led to less favourable treatment toward Canadian livestock. The discriminatory 
treatment occurred when the COOL measure imposed became burdensome to the producers and processors of livestock. The labelling involved higher cost for record-keeping and verification. Furthermore, it was suggested that if the technical regulation adopted by a member state adversely affects the competitive opportunities of the imported products, it would result to less favourable treatment and discrimination towards those products.

By applying the principle adopted in the US COOL, the implementation of nano labelling measure will incur an additional economic cost to manufacturers. Specifically, the higher cost of mandatory labelling may arise from; (i) detecting, characterising, or quantifying ENMs in food products, (ii) revising or designing new label, and (iii) educational or promotional purpose (Reimhult, 2017; Grieger, 2016). However, the US COOL's case differs significantly from the present labelling measure, whereby the additional cost would only be incurred onto foreign importers. As for the labelling of nanofood, both the importers and domestic manufactures would have to bear the same cost. Hence, imported nanofood is not subjected to less favourable treatment.

The provisions of Article 2.2 prohibits the imposition of technical regulation that would lead to unnecessary obstacles to international trade. Article 2.2 states that the "technical regulations shall not be more trade-restrictive than necessary to fulfil a legitimate objective, taking into account the risks non-fulfilment would create (emphasis added)". The article established two requirements that must be fulfilled before mandatory labelling is permissible and ensures any unnecessary obstacles to international trade. Firstly, the objective for mandatory labelling of nanofood must be fulfilled before granting the necessary permits and authorisations. Second, the mandatory labelling measure adopted should not be traderestrictive.

Article 2.2 provides valid examples of objectives for the protection of human and wildlife health and safety, and preservation of the environment. The main objective of mandatory labelling is to protect consumers' right to recognise the ingredients during food production and ensure informed decisions can be made on nanofood. Consumers must be well-informed when making decisions due to the potential risks of safety and health associated with ENMs. Therefore, the objective of mandatory labelling of nanofood is legitimate for the protection of consumers' safety and health.

In addition, the mandatory labelling measure must not be trade-restrictive. The Appellate Board in the case of United States - Measures Concerning the Importation, Marketing and Sale of Tuna and Tuna Products (2012) WT/DS381/AB/R (US-Tuna II (Mexico)) stated that trade restrictiveness refers to the measure that has a limiting effect on trade. Furthermore, the Appellate Board in the US-COOL's case had states that to establish trade-restrictiveness, it is not necessary to demonstrate any actual trade effects. In other words, it is sufficient to prove that the measure affects the competitive opportunities of the imported products. Therefore, if the unlabelled nanofood is not allowed to enter the domestic market, it will give limiting effects on the trade of imported nanofood. The imported nanofood will lose its competitive 
opportunities in the domestic market, thus making the mandatory labelling measure more trade-restrictive than necessary that creates obstacles and barriers to international trade.

However, member states may argue that even mandatory labelling is trade-restrictive, and that labelling is the only effective measure to achieve its main objective. Although there are two alternatives; voluntary marking system and consumer product inventories where both are not trade-restrictive, such measures are incompatible as labelling measures (Dekkers et al., 2007; Hansen, 2016). For instance, product inventory is an online database, whereby consumers could access the database to identify relevant products. On the other hand, the marking system is a voluntary system that relies on the willingness of manufacturers to register their products. Besides, Article 2.2 also allows member states to consider the risks of non-fulfilment. Hence, if labelling measures are not implemented accordingly, there is a possibility that consumers may be continuously exposed to the risks of safety and health issues associated with nanofood. These adverse effects may include reduced sperm parameter, damage to intestinal glades, changes in gastrointestinal tissue and diseases in the liver, kidney, and spleen (Drew \& Hagen, 2016).

Article 2.4 is the last provision in the TBT agreement that provides conditions for a valid labelling measure. Although the mandatory labelling for nanofood is applied for the legitimate objective, i.e. the protection of human safety and health, it is presumed that it would not create any unnecessary obstacles to international trade as it is based on a recognised international standards. Article 2.4 mandates that:

"Where technical regulations are required and relevant international standards exist or their completion is imminent, Members shall use them, or the relevant parts of them, as a basis for their technical regulations except when such international standards or relevant parts would be an ineffective or inappropriate means for the fulfilment of the legitimate objectives pursued [...] (emphasised added)."

The Appellate Board in the US-Tuna II (Mexico) dictated that the technical regulations which are consistent with the relevant international standards will not amount to any unnecessary obstacles on international trade. Moreover, the board further asserted that the international standard refers to a standard that has been established and adopted by an international standardising body or organisation that opens its membership to all states and nations. However, the CAC, CCFL and ISO have never issued or established any standard on mandatory labelling for nanofood. Therefore, mandatory labelling of nanofood is considered an unnecessary obstacle to international trade as the labelling is not part of the international standard.

\section{The SPS Agreement and Mandatory Labelling of Nanofood}

The SPS Agreement is applicable as the objectives of mandatory labelling are to ensure the protection of consumers' right for information, and to protect consumers' safety and health 
with respect to food safety. The SPS Agreement was enforced since 1 January 1995, with the establishment of the WTO. The main focus of the agreement is on food safety, as well as animal and plant health regulations (World Trade Organisation, n.d.). The purpose of the agreement is stated in Annex A. The agreement allows members to "undertake necessary measures to protect human life or health from risks arising from additives, contaminants, toxins or disease-causing organisms in foods, beverages or feedstuffs and diseases carried by animals, plants or products, provided that the safety regulation must not restrain the international trade (emphasised added)". Article 1.1 states that the agreement applies to all SPS measures that directly or indirectly affect international trade. The SPS measures adopted by the member states must be aligned with the provisions of the SPS Agreement that does not cause any restrictions on international trade as outlined under Article 2.

The main principle of the SPS agreement is to standardize the measures adopted by member states. Any forms of SPS measures that are adopted must be based on the existing international standards, guidelines or recommendations as detailed under Article 3.1. Furthermore, Article 3.3 dictates that "sanitary or phytosanitary measures which conform to the international standards, guidelines or recommendations shall be deemed as necessary to protect human, animal or plant life or health, and also presumed to be consistent with the relevant provisions of this Agreement (emphasis added)". Consequently, the mandatory labelling of nanofood is not an international labelling standard. Such labelling measure goes against standardized measures, and therefore, it is considered inconsistent with the SPS Agreement.

If member states adopt the mandatory labelling measure for nanofood into their domestic legislation, it will be considered as a higher standard of labelling than the recognised international labelling standard. Article 3.5 enables members to introduce a sanitary or phytosanitary measure that would result to a higher level of sanitary or phytosanitary protection imposed by the relevant international standards, provided there is a scientific justification for its implementation. In relation to this, members must provide scientific justification either through risk assessment or other scientific evidence to justify the adopted measure. In the proceedings of European Communities - Measures Concerning Meat and Meat Products (Hormones) (2009) WT/DS26/2 (EC-Hormones), it was dictated that members must provide evidence in the risk assessment when implementing or retaining the SPS measure.

Risk assessment is a scientific process to identify, characterise and estimate any potential hazards using available and current information (Fung, Wang, \& Menon, 2018). Therefore, scientific processes must be used as the basis for the labelling measure. The nature and extent of safety and health risks of ENMs continue to be shrouded with uncertainty and are still being investigated till today (Sovalainen \& Pietroiusti, 2017; Larsson, Jansson, $\&$ Boholm, 2019). There are various scientific studies conducted to determine the risks of nanomaterials (Maksimović, Omanović-Mikličanin, \& Badnjević 2019). The toxicity of nanomaterials based on the unique physical and chemical properties of nanoscale materials 
varies from the normal macroscale materials (Sharifi et al., 2012). Scientific studies suggest that an increase in oral exposure to nanomaterial through the gastrointestinal tract could lead to numerous unintended health hazards. Hence, the application of nanotechnology in food and agricultural industry requires a regulatory system that manages the risks associated with nanofood (Adeyeye \& Fayemi, 2019).

This study suggests that the evidence from independent scientific studies is appropriate to illustrate the nature and extent of risks associated with ENMs, and justifies the labelling measure under the SPS Agreement. Nevertheless, if the relevant scientific evidence is insufficient to determine the risks associated with nanofood, member states are allowed to adopt the mandatory labelling measure based on the available information. Article 5.7 of the SPS Agreement states that if scientific evidence is sufficient, members may adopt the provisional SPS measures based on the available current information. The provisional measures include measures adopted by the relevant international organisations, and SPS measures implemented by other Members. However, member states must provide further scientific evidence within a reasonable period. If the evidence is not provided within the prescribed time, mandatory labelling measure must be removed from the states' domestic legislation as it contradicts with the SPS Agreement.

\section{Findings and Recommendations}

Based on the discussions, this study presents three significant findings. Firstly, the Codex standard is the most crucial document for food labelling. Although the standard is not part of the WTO system, it directly impacts the decisions made by members of the WTO. The standards issued by the CAC are acknowledged in the TBT Agreement and SPS Agreement to preserve the international food trade between member states (Buckingham, 2000). It is concluded that the mandatory labelling measure for nanofood is not an international standard for food labelling, and therefore, it is considered an unnecessary barrier to the international trade, under the provisions of Article 2.4 of the TBT Agreement.

To align the mandatory labelling measure with the WTO agreements, it is suggested that the CAC carry out the similar role it undertook on biotechnology foods, whereby the CCFL issued a guideline to its members on the labelling of food derived from modern biotechnology (Codex Alimentarius, n.d.). This study further suggests that the CAC and CCFL must take full responsibility on the implementation of this measure and introduce international guidelines for nanofood labelling due to the increasing application of nanotechnology in the food and agricultural industries, and the rise of safety and health concerns towards nanofood. Furthermore, addressing this issue at its source is more effective than removing the barrier imposed for the protection of rights and interest of the domestic consumers.

The second finding in this study is on issue of like products under the TBT Agreement. This study suggests that the physical properties of nanofood and end uses of ENMs are distinct from conventional food and macro scale materials. However, this study was 
unable to analyse the third criteria of like product from the Border Tax Adjustment's case, namely consumers' perceptions and behaviour towards the products as this requires a systematic survey on consumers' preferences. The Appellate Board in the case of European Communities - Measures Affecting Asbestos and Products Containing Asbestos (2001) WT/ DS135/12 (EC-Asbestos) stated that consumers' tastes and habits are pivotal to determine the 'likeness' and market competitiveness of the product in dispute. Hence, member states should conduct a systematic study to assess consumers' taste and habits towards nanofood. The study should include a detailed examination on the market share of nanofood, such the estimated types and volume of nanofood that are currently available in the market. In the context of Malaysia, this study can be conducted with the collaboration between the Ministry of Health and any institution of higher learning.

The last finding in this study indicates that the objective of labelling measure must comply with the necessary WTO agreements. The objective of mandatory labelling measure for nanofood is based on the protection of consumers' rights to be informed, and the protection of consumer's safety and health. Therefore, member states will need to incorporate the provisions of both the TBT Agreement and SPS Agreements. On the contrary, if the mandatory labelling is adopted solely on the ground of consumers' protection, member states will only need to incorporate the provisions of the TBT Agreement. Based on the Appellate Board's decision, in the case of US-COOL, consumer protection is considered a legitimate objective. Furthermore, when the labelling measure is solely motivated for the protection of safety and health, the SPS Agreement must be incorporated as the agreement includes provisions on the requirements for scientific evidence on food safety. Therefore, it is suggested that member states should focus on either one of the objectives to avoid any complications from the two different WTO Agreements.

\section{Conclusion}

The labelling of food products that contain new technologies, such as nanotechnology, has been adopted by governments of certain countries like the EU to inform consumers and address concerns over the uncertainty of health and safety risks. The mandatory labelling of nanofood is not permissible under the WTO agreements. Mandatory labelling imposes unnecessary barriers to the international trade as it is trade restrictive. If member states decide to adopt mandatory labelling, the measure may compromise the TBT Agreement and SPS Agreement. Furthermore, the implementation of mandatory labelling is not consistent with Article 2.4 of the TBT Agreement as it is not a recognised international standard. If the domestic food regulatory authority bans the unlabelled nanofood from entering the domestic market, such a measure is considered trade-restrictive and contradicts the provisions of Article 2.2. In addition, the labelling measure also contradicts with the provisions of Article 3.3 of the SPS Agreement, whereby the measure is deemed a higher standard than the standard prescribed by the international organisation. Members of the WTO who insist on introducing mandatory labelling are permitted to adopt the measure. 
However, if the implementation of mandatory labelling results to the banning of imported unlabelled nanofood in the domestic market, this measure will contradict the international trade policies. The labelling measure can be contested and refuted by other WTO members as the measure is not in accordance to the provisions of the WTO agreements.

\section{Acknowledgement}

This research is financially supported by the Ministry of Education under the research grant no. FRGS/1/2019/SSI10/UITM/03/1.

\section{References}

Abdollahi, M., \& Azar, S. K. (2019). Trade in nanotechnology: Can the WTO provide an objective balance between the risks and benefits?. Global Trade and Customs Journal, 14(11), 553-562.

Adeyeye, S. A. O., \& Fayemi, O. E. (2019). Nanotechnology and food processing: Between innovations and consumer safety. Journal of Culinary Science \& Technology, 17(5), 435-452. https://doi.org/10.1080/15428052.2018.1476276

Ahmad Shafiee, Y., \& Yeon, A. L. (2016). Trade-related environmental measures under the World Trade Organization (WTO) in Malaysia: The analysis of its' application. Journal of International Studies (JIS), 12, 53-64.

Amenta, V., Aschberger, K., Arena, M., Bouwmeester, H., Botelho Moniz, F., Brandhoff, P., ... Peters, R. J. (2015). Regulatory aspects of nanotechnology in the agri/feed/ food sector in EU and non-EU countries. Regulatory Toxicology and Pharmacology, 73(1), 463-476. https://doi.org/10.1016/j.yrtph.2015.06.016

Buckingham, D. (2000). The labeling of GM foods: The link between Codex and the WTO. AgBioForum. 3(4), 209-212.

Capon, A., Gillespie, J., Rolfe, M., \& Smith, W. (2015). Comparative analysis of the labelling of nanotechnologies across four stakeholder groups. Journal of Nanoparticle Research, 17(8), 327. https://doi.org/10.1007/s11051-015-3129-8

Chuah, A. S., Leong, A. D., Cummings, C. L., \& Ho, S. S. (2018). Label it or ban it? Public perceptions of nanofood labels and propositions for banning nanofood applications. Journal of Nanoparticle Research, 20(2), 36. https://doi.org/10.1007/ s11051-018-4126-5

Codex Alimentarius. (n.d.). International Food Standards, Biotechnology. Retrieved from http://www.fao.org/fao-who-codexalimentarius/thematic-areas/biotechnology/en/.

D'Silva, J., \& Bowman, D. M. (2010). To label or not to label? It's more than a nanosized question. European Journal of Risk Regulation, 1(4), 420-427. https://doi. org/10.1017/s1867299x00000891

Dekkers, S., Prud 'homme De Lodder, L. C. H., De Winter, R., Sips, A. J. A. M., \& De Jong, W. H. (2007). Inventory of consumer products containing nanomaterials. RIVM letter report 340120001 . 
Drew, R., \& Hagen, T. (2016). Potential health risks associated with nanotechnologies in existing food additives. Food Standards Australia New Zealand, Melbourne, Australia. European Parliament. (2014). Nanofoods: MEPs object to new labelling rules. Retrieved from http://www.europarl.europa.eu/news/en/headlines/society/20140313STO38801/ defining-nano-food-a-big-problem-at-a-very-small-scale

Food and Drug Administration. (2007), Nanotechnology a report of the US Food and Drug Administration Nanotechnology Task Force, Rockville, Maryland. Author.

Fung, F., Wang, H. S., \& Menon, S. (2018). Food safety in the 21st century. Biomedical Journal, 41(2), 88-95. https://doi.org/10.1016/j.bj.2018.03.003

Grieger, K. D., Hansen, S. F., Mortensen, N. P., Cates, S., \& Kowalcyk, B. (2016). International implications of labeling foods containing engineered nanomaterials. Journal of food protection, 79(5), 830-842. https://doi.org/10.4315/0362-028x.jfp-15-335

Gruère, G. P. (2011). Labeling nano-enabled consumer products. Nano Today, 6(2), 117121. https://doi.org/10.1016/j.nantod.2011.02.005

Hansen, S. F., Heggelund, L. R., Besora, P. R., Mackevica, A., Boldrin, A., \& Baun, A. (2016). Nanoproducts-what is actually available to European consumers?. Environmental Science: Nano, 3(1), 169-180. https://doi.org/10.1039/c5en00182j

Hoseinnejad, M., Jafari, S. M., \& Katouzian, I. (2017). Inorganic and metal nanoparticles and their antimicrobial activity in food packaging applications. Critical Reviews in Microbiology, Critical Reviews in Microbiology, 44(2), 161-181. https://doi.org/10. 1080/1040841x.2017.1332001

International Standard Organisation. (2013). ISO/TS 13830:2013 Nanotechnologies — Guidance on voluntary labelling for consumer products containing manufactured nano-objects, Geneva, Switzerland: Author.

Jampilek, J., Kos, J., \& Kralova, K. (2019). Potential of nanomaterial applications in dietary supplements and foods for special medical purposes. Nanomaterials, 9(2), 296. https://doi.org/10.3390/nano9020296

Joseph, T., \& Morrison, M. (2006). Nanoforum report: Nanotechnology in agriculture and food. Retrieved from Nanoforum website: https://www.nanowerk.com/ nanotechnology/reports/reportpdf/report61.pdf

Karlaganis, G., \& Liechti, R. (2013). The regulatory framework for nanomaterials at a global level: SAICM and WTO Insights. Review of European, Comparative \& International Environmental Law, 22(2), 163-173. https://doi.org/10.1111/reel.12031

Karlaganis, G., Liechti, R., Teparkum, S., Aungkavattana, P., \& Indaraprasirt, R. (2019). Nanoregulation along the product life cycle in the EU, Switzerland, Thailand, the USA, and intergovernmental organisations, and its compatibility with WTO law. Toxicological \& Environmental Chemistry, 101(7-8), 339-368. https://doi.org/10.1 080/02772248.2019.1697878

Keane, S. (2006). Can a consumer's right to know survive the WTO: The case of food labelling. Transnat'l L. \& Contemp. Probs., 16, 291.

Larsson, S., Jansson, M., \& Boholm, A. (2019). Expert stakeholders' perception of nanotechnology: Risk, benefit, knowledge, and regulation. Journal of Nanoparticle Research, 21(3), 57. https://doi.org/10.1007/s11051-019-4498-1 
Lakshmi, S. J., Roopa Bai, R. S., Sharanagouda, H., Ramachandra, C. T., Nadagouda, S., \& Nidoni, U. (2018). Effect of biosynthesized zinc oxide nanoparticles coating on quality parameters of fig (Ficus carica L.) fruit. Journal of Pharmacognosy and Phytochemistry, 7(3), 10-14.

Li D. (2014). Labeling of genetically modified organisms: Law, science, policy and practice. (Doctoral dissertation) University of Alberta, Alberta, Canada.

Maksimović, M., Omanović-Mikličanin, E., \& Badnjević, A. (2019). Is Nanofood Safe?. In Nanofood and Internet of Nano Things (pp. 87-137). Springer, Cham. https://doi. org/10.1007/978-3-030-15054-9 3

Orden, D., \& Roberts, D. (2007). Food regulation and trade under the WTO: Ten years in perspective. Agricultural Economics, 37, 103-118. https://doi.org/10.1111/j.15740862.2007.00238.x

Peters, R. J., Bouwmeester, H., Gottardo, S., Amenta, V., Arena, M., Brandhoff, P., ... \& Rauscher, H. (2016). Nanomaterials for products and application in agriculture, feed and food. Trends in Food Science \& Technology, 54, 155-164. https://doi. org/10.1016/j.tifs.2016.06.008

Rahmah Ismail. (2011). Food and consumer protection: A study on food legislation of selected countries (No. 017). ASLI Working Paper.

Ramkumar, C., Vishwanatha, A., \& Saini, R. (2019). Regulatory aspects of nanotechnology for food industry. Nanotechnology Applications in Dairy Science: Packaging, Processing, and Preservation, 169. https://doi.org/10.1201/9780429425370-7

Ranjan, S., Dasgupta, N., Singh, S., \& Gandhi, M. (2019). Toxicity and regulations of food nanomaterials. Environmental Chemistry Letters, 17(2), 929-944. https://doi. org/10.1007/s10311-018-00851-z

Ravichandran, R. (2010). Nanotechnology applications in food and food processing: Innovative green approaches, opportunities and uncertainties for global market. International Journal of Green Nanotechnology: Physics and Chemistry, 1(2), P72-P96. https://doi.org/10.1080/19430871003684440

Reimhult, E. (2017). Nanoparticle risks and identification in a world where small things do not survive. Nanoethics, 11(3), 283-290. https://doi.org/10.1007/s11569-017-0305-6

Sharifi, S., Behzadi, S., Laurent, S., Forrest, M. L., Stroeve, P., \& Mahmoudi, M. (2012). Toxicity of nanomaterials. Chemical Society Reviews, 41(6), 2323-2343. https://doi. org/10.1039/c1cs15188f

Snir, R. (2013). Governance by disclosure: Transnational convergence in the field of nanotechnology. Transnational Environmental Law, 2(1), 69-94. https://doi. org/10.1017/s2047102513000034

Sovalainen, K., \& Pietroiusti. A. (2017). In B. Fadeel, (Eds.), Adverse effects of engineered nanomaterials: Exposure, toxicology, and impact on human health (pp. 103-120). United Kingdom. Academic Press.

Tang, S., Wang, M., Germ, K. E., Du, H. M., Sun, W. J., Gao, W. M., \& Mayer, G. D. (2015). Health implications of engineered nanoparticles in infants and children. World Journal of Pediatrics, 11(3), 197-206. https://doi.org/10.1007/s12519-015-0028-0

Thayer, J. D. (2005). The SPS Agreement: Can it regulate trade in nanotechnology?. Duke Law \& Technology Review, 4(1), 1-16. 
Thow, A. M., Jones, A., Hawkes, C., Ali, I., \& Labonté, R. (2017). Nutrition labelling is a trade policy issue: Lessons from an analysis of specific trade concerns at the World Trade Organization. Health Promotion International, 33(4), 561-571. ttps://doi. org/10.1093/heapro/daw109

UNCTAD. (2003). Dispute Settlement: World Trade Organization, Technical Barrier to Trade. New York, United States. Author.

United Nation Trade Statistic. (2017). Harmonized Commodity Description and Coding Systems (HS). Retrieved from https:/unstats.un.org/unsd/tradekb/ Knowledgebase/50018/Harmonized-Commodity-Description-and-Coding-SystemsHS

World Health Organisation. (2015). Food safety: What you should know. Retrieved from http://www.searo.who.int/entity/world_health_day/2015/whd-what-you-shouldknow/en/

World Trade Organisation. (2014). The World Trade Organisation. Geneva, Switzerland. Author.

World Trade Organisation. (2018). WTO in Brief. Geneva, Switzerland. Author.

World Trade Organisation. (2019). Annual Report 2019. Geneva, Switzerland. Author.

World Trade Organisation. (n.d.). Sanitary and Phytosanitary Measures: Introduction Understanding the WTO Agreement on Sanitary and Phytosanitary Measures. Retrieved from https://www.wto.org/english/tratop_e/sps_e/spsund_e.htm 